\title{
SILAE Special Issue: Italo-Latin American Ethnoknowledge and Research on Medicinal Plants
}

\author{
Suzana G. Leitao, ${ }^{1}$ Luca Rastrelli ${ }^{2}$
}

\author{
${ }^{1}$ Departamento de Produtos Naturais e Alimentos, Faculdade de Farmácia, Universidade \\ Federal do Rio de Janeiro, Brazil (sgleitao@pharma.ufrj.br); \\ ${ }^{2}$ Dipartimento di Scienze Farmaceutiche e Biomediche, University of Salerno, Italy \\ (rastrelli@unisa.it).
}

The Italo-Latin American Society of Ethnomedicine (SILAE, www.silae.it) is an international non-profit organization dedicated to advancing science around the world by serving as an educator, leader, spokesperson and professional association. The fundamental objective of SILAE is to promote research and development into the use of medicinal and food plants in different countries of the World. SILAE welcomes and actively seeks opportunities to work cooperatively, activating and intensifying scientific relations between countries and between SILAE members. Since SILAE was founded (1990) its objective has been set to contribute to the close examination of the themes of great interest and actuality in the context of the relationships between Latin America and the European Union. In addition to this, SILAE aimed to individualize new ways of collaboration between its member countries and other European as well as Asiatic countries to sign accords with intergovernmental organizations. SILAE proposes to establish contacts with Scientific Communities, Universities, and Research Centres for the pursuit of medicinal and food plants knowledge. Moreover SILAE_live, the one-to-one live Chat and Messenger on our website (www.silae.it), is the first scientific chat on the web and is a developed tool to engage the interest and imagination of the public and for helping nonscientists to understand and enjoy scientific discoveries and the scientific processes.

In addition to organizing membership activities, SILAE publishes the SILAE Special Issues, as well as many scientific newsletters, books and reports, and spearheads programs that raise the bar of understanding for science worldwide.

Revista Brasileira de Farmacognosia Brazilian Journal of Pharmacognosy is publishing a special issue that contains a selection of papers that were presented at the XIX SILAE Congress (Cagliari, Italy, September, 6-10, 2010). For the Conference, 292 papers from authors coming from 19 different countries were accepted and published in the Proceedings of the SILAE 2010 (Abstract book ISBN: 88-8160-218-0). The most promising 30 submissions were proposed for publication in the special issue of Revista Brasileira de Farmacognosia - Brazilian Journal of Pharmacognosy in October 2010, each of which was reviewed by at least two anonymous referees. Following the review, 21 papers from different universities of Argentina (1), Brazil (7), Costa Rica (1), Cuba (1), Ireland (1), Italy (7), Mexico (2) and Venezuela (1) were selected for publication in this Special Issue. They are original papers on all aspects of natural products including ethnobotany/ethnopharmacology, isolation and characterization of natural products, biological activities, analytical methods and sensory analysis; several are collaborative works between two or more countries.

This Revista Brasileira de Farmacognosia - Brazilian Journal of Pharmacognosy special issue provided an opportunity for publication of original, peer-reviewed, fulllength articles on new research on medicinal plants used in Latin America; this will serve to stimulate the studies in these areas that are extremely important for academia and industry. The Guest Editors would like to thank the contributors who gave so generously of their time and experience and who made this publication a valuable tool for scientists in the field of natural products chemistry and biology. Thanks are also due to the referees for their valuable comments and for the very detailed and accurate review of manuscripts; their comments certainly helped to improve the papers. We are also very grateful to Prof. Cid Santos Editor in Chief of Revista Brasileira de Farmacognosia - Brazilian Journal of Pharmacognosy for embracing this project with interest and enthusiasm, and for the opportunity to publish this Special Issue. I hope that this will be the first of a long series in this attractive and interesting Journal. 